\title{
Occupational lung cancer among fisherman: a triple case report
}

\author{
Tarik Ghailan $^{1}$, Mustapha El Ftouh ${ }^{1,2}$ \\ ${ }^{1}$ Centre des Etudes Doctorales SVS, Faculté de Médecine et de Pharmacie, Université MED V, \\ Rabat, Av. Mohamed Belarbi El Alaoui, Rabat Institut, Rabat, Morocco \\ ${ }^{2}$ Service de Pneumologie du CHU Ibn Sina de Rabat, Mfadel Cherkaoui, Rabat Instituts, Rabat, Morocco
}

\begin{abstract}
Background: The World Health Organisation places lung cancer as the leading cause of cancer mortality in the world. The fishermen are one of the most important consumers of tobacco, which remains the main risk factor for lung cancer. However, there are no epidemiological data on the role of other causes, particularly occupational ones, in genesis of this disease. The objective of our work is to expose medical and occupational data of 3 fishermen with lung cancer and discuss a possible occupational origin of their pathology. Case presentation: This is a case report where we describe medical and occupational data of 3 fishermen working in the port of Tangier (Morocco) who have lung cancer. The first one is an ordinary fisherman, the second is a mechanic on board and the third is an ordinary fisherman but who worked 21 years ago aboard deep-sea fishing ships as a helper in the mechanic room. All fishermen were in the fifties; the third one never smoked while the other two were described as heavy smokers. All of them were exposed during their daily work to some chemicals liable to cause lung cancer. The anatomopathological types found were 2 cases of adenocarcinoma which is the histopathological variant often found in cases of occupational origin and one case of squamous cell carcinoma.

Conclusions: The results obtained after studying these 3 cases suggest the possibility of occupational origin in the genesis of lung cancer among fishermen; however, the increased smoking rate in this population remains the most probable factor and helps the preventive approach to be adopted. More detailed epidemiological studies would highlight the possible role of occupational causes in the carcinogenesis of this pathology.
\end{abstract}

(Int Marit Health 2018; 69, 1: 46-50)

Key words: lung cancer, fisherman, occupational exposure, tobacco

\section{INTRODUCTION}

The World Health Organisation places the lung cancer as the leading cause of cancer mortality in the world [1]. Indeed, it is the first cause of cancer death for men and the second for women, coming just after women's breast cancer [2]. Smoking is the main risk factor and the carcinogenic effect of tobacco on the lung has been demonstrated since 1950 [3]. The relative risk of lung cancer for smokers compared to non-smokers is about 8-15 times among men, and 2-10 times among women. However; recent studies show an increase in occupa- tional and environmental factors in the genesis of this pathology $[4,5]$.

The danger and complexity of working at sea has been known since antiquity and the register of occupational diseases of fishermen continues to grow, including, among others, neoplastic pathologies [6]. If epidemiological studies showed that lip cancer remains the first malignant pathology among fishermen [7], lung cancer would also have an interesting place in this high tobacco-consuming category [8]. However, it is also necessary to question about the place of occupational nuisances as an aetiology of this neoplasm. 
The objective of our work is to expose some occupational and medical data of 3 fishermen with lung cancer in order to discuss a possible occupational origin of their pathology.

\section{CASE PRESENTATION}

This is a case report in which we describe medical and occupational data of 3 fishermen working in the port of Tangier (Morocco) who suffered from lung cancer.

\section{PATIENT 1}

Mr. M.H., 59 years old, fisherman for 42 years, always aboard artisanal fishing boats, smoker at the rate of 20.5 pack/year (10 cigarettes per day since the age of 18), a cannabis consumer for more than 30 years. Navigations were diurnal, lasting from 8 to 12 hours; there was no notion of night work. In his medical history we particularly note a recurrent cough with sputum probably related to chronic bronchitis for which he received a treatment.

Since 6 months this cough became dry, more and more severe, accompanied by bloody sputum, all in a context of unencrypted weight loss. No other signs were noted, in particular there was no dyspnoea. A specialised consultation by a pulmonologist showed on a chest X-ray an irregular opacity at the right upper lobe. The thoracic computed tomography (CT) scan showed a lesion of $38 \mathrm{~mm}$ diameter, excavated, with spiculated contours, contrast-enhancing, associated with three ipsilateral lymphadenopathies of the pulmonary helium. The histopathological examination of the bronchial biopsy performed during a bronchial fibroscopy revealed a moderately differentiated adenocarcinoma.

Medical examinations for metastases detection with cerebral CT scan, bone scintigraphy and abdomino-pelvic CT scan showed no pathologic finding. The patient received a right upper lobectomy with lymph node dissection. The histopathological examination confirmed the diagnosis with lymph node involvement, the patient then received 4 sessions of chemotherapy.

\section{PATIENT 2}

Mr. M.H., 53 years old, a mechanic for 25 years aboard coastal fishing vessels, previously working as a mechanic in a car repair workshop for 7 years, the navigations lasted averagely 48 to 72 hours with night work and frequent insomnia. The notion of occupational stress was present and evoked by the fishermen. He was a smoker at the rate of 66 pack/year (20 cigarettes/day for 33 years) and an occasional alcohol consumer. No significant personal or family medical history was found except repeated episodes of epigastralgia treated by various antacids.

One year ago, the patient experienced a cough with dyspnoea recently followed by haemoptysis. However, the patient refused all sort of medical consultation which was ultimately carried out following the alteration of its general condition with weight loss and a global invalidity caused by his dyspnoea. The chest X-ray showed opacity of the left upper lobe extending to the left hilum. Thoracic CT scan revealed a tumour image obstructing the left upper lobe bronchus and massively invading the pulmonary hilum as well as the left atrium through the upper left pulmonary vein. It also showed left antero-mediastinal lymphadenopathies but no contralateral lymphadenopathies were found. Histopathological examination of a bronchial biopsy revealed a slightly differentiated squamous cell carcinoma.

No metastasis was found and the patient was classified cT4N2MO according to the International Association for the Study of Lung Cancer (IASLC; stage IIIB). The patient then received a treatment combining 6 cycles of chemotherapy followed by sequential radiotherapy.

\section{PATIENT 3}

Mr. E.M., 50 years old was a fisherman for 32 years; he was working as an ordinary fisherman on a coastal fishing trawler for 5 years, but previously he had worked for 21 years on deep-sea fishing vessels as an assistant in the engine room. During the first 6 years of his career he had worked as an ordinary fisherman on board of an artisanal fishing boat. He is a non-smoker and no notion of other addiction was found. The navigations lasted 2-3 days and when he worked in deep sea fishing he use to sail for 3 continuous months at sea. The patient has never had medical history.

On a chest X-ray performed during a routine screening carried out by the fishermen's doctor about a case of tuberculosis in a crew member, the radiologist noted a suspicious image of the right upper lobe for which he proposed to complete the medical imaging examination with a thoracic CT scan which found a lesion of $19 \mathrm{~mm}$ diameter, with irregular contours, contrast-enhancing. No lymphadenopathy was found. At this stage of the disease, the patient showed no clinical signs. Bronchial fibroscopy with anatomopathological examination found a well differentiated adenocarcinoma.

No metastasis was found. The patient received a right upper lobectomy with lymph node dissection. Anatomopathological examination of the surgical specimen confirmed the diagnosis.

\section{DISCUSSION}

The first and the second patients were known to be smokers; in fact, smoking remains the main risk factor for lung cancer [3]. This addiction is clearly higher among fishermen compared to the general population; a study showed a smoking rate of $68.1 \%$ among Moroccan fishermen (versus $18 \%$ for general population) [6]. This rate is 
even higher among our neighbour fishermen in Andalusia (Spain): 81.2\% [9]. An Italian study involving 7530 fishermen in northeastern Italy concluded that the greatest health hazard among this population is lung cancer, and the factor involved in this risk is smoking [10]. In this study the quantity of tobacco smoked was proportional to the number of hours spent at sea.

The first patient consumed cannabis, the role of cannabis as a new causal agent of the lung cancer has been well demonstrated [11]. However, in this patient the attribution of imputability only to cannabis would be difficult because he was also a heavy smoker. The third patient is a non-smoker; this situation highlights other non-smoking causes of lung cancer. Moreover, several studies suggest that the recent increase in this cancer prevalence may be related to other factors such occupational ones [7]. Indeed, the fisherman, because of his daily work, is well exposed to some chemicals recognised as carcinogenic by International Agency for Research on Cancer with bronchopulmonary tropism; this is the case of the mechanic fisherman in our second case who was exposed to benzene and benzopyrene contained in the exhaust gases emitted during navigation. This exposition is more important during engine maintenance operations and more particularly during assembly/disassembly of the carburettors [12]. Indeed, this fisherman who worked 25 years on board costal fishing vessels ( 2 longliners and a trawler) says that the engines he worked on (engines from 150 to 200 horsepower all powered by diesel) were often in a precarious state, leakages of diesel exhaust ducts were quite frequent invading the restricted space of the engine room and failures in full navigation were not uncommon. He also claims that his interventions on these machines were very frequent, exposing him permanently to the diesel exhaust. This substance is known to be carcinogenic for the lungs [13]. However, this risk remains lower than that of merchant ships seamen and mainly those of oil tankers. It is also shown that the risk of lung cancer is particularly increased among engine room seamen [12]; this is the situation of our third patient who had worked for 21 years in the engine room aboard deep-sea fishing vessels (with 750 horsepower engines powered by diesel). The occupational origin is quite pronounced in this situation because this fisherman has never smoked before. He worked as a greaser mechanic where he was exposed to exhaust (diesel) but he was mostly in contact with different chemicals, mainly lubricants which constitutes a source of exposure to polycyclic aromatic hydrocarbons. This exposure leads to a significant risk of lung and bladder cancers. The skin is the main way of penetration of these products, especially during skin contact with those lubricants widely used in the engine room [12].

The occupational exposure has been also found in the case of the artisanal fisherman in our first case, who claims that he was himself who carried out maintenance operations, painting and anti-fouling treatments on a regular basis. Indeed, these operations utilize paint that previously contained asbestos, such as Bitulatex ${ }^{\circledR}$-type paints, and also use products with crystalline silica, two components that are at risk for lung cancer [14].

We must not forget the effect of the interaction between different carcinogens for the lungs to which these fishermen were exposed at the same time. This is the situation experienced by the first fisherman who was a smoker and exposed to asbestos contained in the paintings. The concomitant effect of these two substances on the risk of lung cancer is compatible with a multiplicative model; for a person exposed to asbestos, the risk of lung cancer is increased by exposure to tobacco, which can increase the risk of developing this cancer by 50 times compared to an unexposed person [15]. This is also the case of the fisherman of the second observation who was a smoker and exposed to diesel exhaust; a case study on lung cancer among Swedish dockworkers exposed to diesel exhaust and smoking confirmed a strong interaction between these two factors [16]. Similarly, it is well established that in workers exposed to polycyclic aromatic hydrocarbons, smoking causes more serious DNA oxidative damage than in non-exposed individuals, which may play the pivotal role in the carcinogenic mechanism of lung cancer [17].

Another debate arises about occupational expositions; it is that of the workers versatility who have worked in various occupations. This has consequences in terms of poly-exposures and co-exposures which makes it difficult to attribute the role of each exposure in the development of the disease.

This is the situation with the second patient who had previously worked in an automobile repair shop where he was exposed to the exhaust gases as on board, but also to other products that are also recognised carcinogenic to the lungs. This is the case, for example, for asbestos contained in brakes and clutch discs.

This is also the situation for the third patient who, in addition to his special work in deep-sea fishing as assistant in the engine room, had worked at the beginning of his career in artisanal fisheries where the occupational exposures - as we saw for the first patient - have nothing to do with those of the deep-sea fishing.

Finally, some factors that characterise this population can also be discussed.

Fishermen, particularly in Morocco belong to a disadvantaged and very vulnerable socio-professional category which adopts an unhealthy lifestyle with innumerable habits harmful to health [18]. An association between lung cancer risk and socioeconomic level is well described with the highest rates generally observed among disadvantaged social classes [19]. However, the socio-professional cate- 
gory is not a risk factor per se, as these social differences are undoubtedly underpinned by other risk factors, such as higher smoking rate in lower socio-occupational categories, but also an important occupational exposure due to low preventive culture and as well an unhealthy diet. The proportions with which these risk factors are involved are still widely discussed, particularly with regard to smoking, even if all the opinions agree that it explains an important part of these social inequalities [19, 20].

Also, many studies wondered about the role of occupational stress in the genesis of various cancers and more particularly of lung cancer [21]. This occupational factor was present in the fisherman of the second case because of his important responsibility on board as a mechanic, especially when it comes to sail aboard some vessels with dilapidated engine conditions. Literature shows that fishermen are an important target for work-related stress due to the specificities of their work and their special working conditions on board; a study in the north of Morocco found a rate of $52.6 \%$ of occupational stress among fishermen [22].

The anatomopathological type of the occupational lung cancer doesn't exhibit particular histopathological specificities for some authors [23]; however, several studies show the increasing incidence of adenocarcinoma, a histological type that would be more frequent in occupational cancers [24]. This carcinoma type was present in our first case and, especially in the last one which could suggest an occupational origin for this patient as long as it's here a non smoker lung cancer.

\section{CONCLUSIONS}

The findings revealed by these 3 cases would suggest an occupational origin in the genesis of lung cancer among fishermen; however, the increased tobacco consumption within this population remains the most probable factor and emphasizes the need for an anti-smoking preventive plan for this category of workers and for improving the medical care. The interaction between different factors that cause this cancer makes the role of each of them in the carcinogenesis process even more difficult to establish. Well-defined epidemiological studies among these workers could explain the possible role of occupational exposures in the development of this neoplasm.

\section{REFERENCES}

1. WHO (World Health Organization). World Cancer Report 2008. Lyon: IARC Press; 2008.

2. Alberg AJ, Ford JG, Samet JM, et al. American College of Chest Physicians. Epidemiology of lung cancer: ACCP evidence-based clinical practice guidelines (2nd edition). Chest. 2007; 132(3 Suppl): 29S-55S, doi: 10.1378/chest.07-1347, indexed in Pubmed: 17873159 .

3. IARC (International Agency for Research on Cancer) Working Group on the Evaluation of Carcinogenic Risks to Humans. Tobacco Smoke and involuntary Smoking. IARC Monogr Eval Carcinog Risks Hum. Vol 83. Lyon; 2004.

4. López-Cima MF, García-Pérez J, Pérez-Gómez B, et al. Lung cancer risk and pollution in an industrial region of Northern Spain: a hospital-based case-control study. Int J Health Geogr. 2011; 10: 10, doi: 10.1186/1476-072X-10-10, indexed in Pubmed: 21266041.

5. Menvielle G, Boshuizen $\mathrm{H}$, Kunst AE, et al. The role of smoking and diet in explaining educational inequalities in lung cancer incidence. J Natl Cancer Inst. 2009; 101(5): 321-330, doi: 10.1093/jnci/ djn513, indexed in Pubmed: 19244178.

6. Ghailan T, Hamdouch I, Bennouna A, et al. Troubles de la vigilance chez les pêcheurs de Tanger. Med Marit. 2009; 9(2).

7. Andersen A, Barlow L, Engeland A, et al. Work-related cancer in the Nordic countries. Scand J Work Environ Health. 1994; 25(Suppl 2): 1-116, indexed in Pubmed: 10507118.

8. Ghailan T, Belhaje M, Aoudi YEl, et al. Évaluation du cannabisme chez les gens de Mer au nord du Maroc. Arch Mal Prof Env. 2012; 73(3): 499, doi:10.1016/j.admp.2012.03.194.

9. Nogueroles Alonso de la Sierra P, Juan Agüera S, Almenara Barrios J, et al. [The tobacco habit among fishermen of the Barbate coast (Cádiz)]. Rev Sanid Hig Publica (Madr). 1992; 66(5-6): 299-305, indexed in Pubmed: 1366228.

10. Mastrangelo G, Malusa E, Veronese $C$, et al. Mortality from lung cancer and other diseases related to smoking among fishermen in north east Italy. Occup Environ Med. 1995; 52(3): 150-153, doi: 10.1136/oem.52.3.150, indexed in Pubmed: 7735384.

11. Sasco AJ, Merrill RM, Dari I, et al. A case-control study of lung cancer in Casablanca, Morocco. Cancer Causes Control. 2002; 13(7): 609-616, indexed in Pubmed: 12296508.

12. Moen BE, Nilsson R, Nordlinder R, et al. Assessment of exposure to polycyclic aromatic hydrocarbons in engine rooms by measurement of urinary 1-hydroxypyrene. Occup Environ Med. 1996; 53(10): 692696, doi: 10.1136/oem.53.10.692, indexed in Pubmed: 8943834.

13. Steenland K, Deddens J, Stayner L. Diesel exhaust and lung cancer in the trucking industry: exposure-response analyses and risk assessment. Am J Ind Med. 1998; 34(3): 220-228, doi: 10.1002/ (sici)1097-0274(199809)34:3<220::aid-ajim3>3.0.co;2-z, indexed in Pubmed: 9698990.

14. Lee KH, Ichiba M, Zhang J, et al. Multiple biomarkers study in painters in a shipyard in Korea. Mutat Res. 2003; 540(1): 89-98, doi: 10.1016/s1383-5718(03)00173-6, indexed in Pubmed: 12972061.

15. Hammond EC, Selikoff IJ, Seidman H. Asbestos exposure, cigarette smoking and death rates. Ann N Y Acad Sci. 1979; 330: 473-490, doi:10.1111/j.1749-6632.1979.tb18749.x, indexed in Pubmed: 294198.

16. Emmelin A, Nyström L, Wall S. Diesel exhaust exposure and smoking: a case-referent study of lung cancer among Swedish dock workers. Epidemiology. 1993; 4(3): 237-244, doi: 10.1097/00001648199305000-00007, indexed in Pubmed: 7685637.

17. Yang J, Zhang $\mathrm{H}$, Zhang $\mathrm{H}$, et al. Smoking modify the effects of polycyclic aromatic hydrocarbons exposure on oxidative damage to DNA in coke oven workers. Int Arch Occup Environ Health. 2017; 90(5): 423-431, doi: 10.1007/s00420-017-1206-2, indexed in Pubmed: 28181029.

18. Ghailan T, Estopá H, Alcolea RM, et al. Comparative study of lifestyles and some unhealthy habits in coastal fishermen of the Tangier region coast (Morocco) and the coast of Catalonia (Spain). Arch Mal Prof. 2013; 74(5): 557-558, doi: 10.1016/j. admp.2013.07.115.

19. Menvielle G, Boshuizen $\mathrm{H}$, Kunst $\mathrm{AE}$, et al. The role of smoking and diet in explaining educational inequalities in lung cancer incidence. 
J Natl Cancer Inst. 2009; 101(5): 321-330, doi: 10.1093/jnci/ djn513, indexed in Pubmed: 19244178.

20. Nkosi TM, Parent MÉ, Siemiatycki J, et al. Socioeconomic position and lung cancer risk: how important is the modeling of smoking? Epidemiology. 2012; 23(3): 377-385, doi: 10.1097/ EDE.0b013e31824d0548, indexed in Pubmed: 22415109.

21. Heikkilä K, Nyberg ST, Theorell T, et al. IPD-Work Consortium. Work stress and risk of cancer: meta-analysis of 5700 incident cancer events in 116,000 European men and women. BMJ. 2013; 346: f165, doi: 10.1136/bmj.f165, indexed in Pubmed: 23393080 .
22. Laraqui $\mathrm{O}$, Laraqui $\mathrm{S}$, Caubet $\mathrm{A}$, et al. Evaluation du stress professionnel chez les gens de mer à Tanger. Med Marit. 2010; 10(1): 38-58.

23. Samet JM, Avila-Tang E, Boffetta P, et al. Lung cancer in never smokers: clinical epidemiology and environmental risk factors. Clin Cancer Res. 2009; 15(18): 5626-5645, doi: 10.1158/1078-0432. CCR-09-0376, indexed in Pubmed: 19755391.

24. Luce D, Stücker I. ICARE Study Group. Investigation of occupational and environmental causes of respiratory cancers (ICARE): a multicenter, population-based case-control study in France. BMC Public Health. 2011; 11(1): 928, doi: 10.1186/1471-2458-11-928, indexed in Pubmed: 22171573. 